\title{
BODY MASS INDEX OF ADOLESCENTS AND ADULTS AND ITS RELATION TO SLEEP IN A WARD OF GOKARNESHWOR MUNICIPALITY
}

\author{
Shrestha $N^{1}$ Shakya $B,{ }^{1}$ Nikhil $O M^{2}$
}

${ }^{1}$ Department of Community Medicine, ${ }^{2}$ Intern, Nepal Medical College Teaching Hospital, Attarkhel, Gokarneshwor-8, Kathmandu, Nepal

\begin{abstract}
Various studies have shown that abnormal body mass index (BMI) of an individual is linked to poor sleep. Abnormal BMI is a predisposing factor for many non-communicable diseases like cardiovascular diseases and diabetes. However, if BMI is affected by sleep, detecting sleep abnormality followed by simple corrective measures may help in making BMI normal hence preventing the risk of many such diseases. Using Asian Classification for BMI and questions from Pittsburgh Sleep Quality Index (PQSI) a survey was carried out among persons aged 15 to 60 years in a ward of Gokarneshwor Municipality. In this study, out of a total of 563 persons $4.4 \%$ were underweight, $33.9 \%$ had normal BMI, $18.5 \%$ were overweight and $43.2 \%$ were obese. Around $22 \%$ reported a reduced duration of sleep but only around $5 \%$ of the persons felt that their quality of sleep was poor. This study showed that the association between reduced sleep duration and abnormal BMI was significant even when confounding variables like tobacco or alcohol and poverty state were removed.
\end{abstract}

\section{KEYWORDS}

Body mass index, sleep,

Gokarneshwor

\section{CORRESPONDING AUTHOR}

Dr Niraj Shrestha

Assistant Professor,

Department of Community Medicine,

Nepal Medical College Teaching Hospital

Gokarneshwor-8, Kathmandu, Nepal

Email: nishre15@gmail.com

Orcid ID: 0000-0002-2974-9088

DOI: https://doi.org/10.3126/nmcj.v22i1-2.30036 


\section{INTRODUCTION}

Body mass index (BMI), also known as Quetelet index, is the ratio of weight in kilograms and height squared in meters. ${ }^{1}$ The term "adolescence" has been defined as including those aged between 10 to $19 .^{2}$ It is the age that precedes adulthood. Humans spend about one-third of their lives in sleep, yet most individuals know little about sleep. Sleep is a universal need of all higher life forms including humans, absence of which has serious physiological consequences. ${ }^{3}$ Major advances in sleep sciences have occurred since the discovery of rapid eye movement (REM) sleep in 1953 AD. ${ }^{4}$ The importance of sleep to good health was shown by the experiments conducted in rats. With sleep deprivation the rats became hyper-metabolic and lost weight despite increasing food intake. Studies of prolonged sleep deprivation have not been performed in humans for ethical reasons. However, there are evidences that torture in humans in the form of prolonged sleep deprivation had detrimental consequences to the individual. ${ }^{4}$

Studies have shown that BMI is affected by sleep. ${ }^{5,6}$ Mechanisms of sleep restriction leading to changes in weight (and BMI) are unclear but it may be due to disrupted appetite regulating hormone. $^{7}$

Sufficient sleep duration requirements vary across the lifespan and from person to person. The recommended duration of sleep by National Sleep Foundation of U.S.A. is 8 to 10 hours for adolescents and 7 to 9 hours for adults. ${ }^{8}$ Results from another study done in U.S.A indicated that professionals should also focus on sleep quality in addition to sleep quantity in their efforts to understand the role of sleep in daily life. ${ }^{9}$ The Pittsburgh Sleep Quality Index (PSQI), a selfadministered questionnaire that assesses sleep quality over a 1-month time interval, has been used on late adolescents. ${ }^{10}$ This index has also been used to assess quality of sleep in adults under the age of sixty. ${ }^{11}$ According to WHO, Asian BMI classification for adults, the suggested cut off point for underweight, overweight and obese I and obese II in $\mathrm{kg} / \mathrm{m}^{2}$ is $<18.5,23.0$ to $24.5,25.0$ to 29.9 and $>30$ respectively with normal range being 18.5 to 22.9. For adolescents BMI categories vary according to age and gender as per WHO growth charts.

\section{MATERIALS AND METHODS}

After getting ethical approvalfrom the Institutional Review Committee of Nepal Medical College (Ref. No:044-075/076) and consent from the Ward office, community based descriptive study was carried out from June 2019 to November 2019 in ward 1 of Gokarneshwor Municipality which has a total of 9 wards.
A questionnaire based on that of Family Health Exercise, Community Medicine Department of Nepal Medical College and PQSI was designed to collect data required for the research. Medical undergraduates of Nepal Medical College were trained to use the questionnaire when they went on a family health visit which is a part of academic activity of Community Medicine. For this permission was taken from the Head of Community Medicine Department. Verbal consent was also taken from the head of each household.

Total number of households in Ward 1 is 1194 (as per Gokarneshwor Municipality, Policy, Program and Budget-2018/19). Two hundred and forty households constitute $20 \%$ of the total number of households in that ward. To cover 20 $\%$ of the total households in this ward, based on method of systematic random sampling, every fifth household was selected. If the members did not give consent the student went to the next household. Pre testing was done in 10 percent of the total households.

Five hundred and sixty- three subjects with age between 15 to 60 years of age from 240 households participated in this study. Anthropometric measurements were taken using a weighing machine and measuring tape. Weight was measured with a weighing scale placed on a hard, flat surface without slippers and reported in kilograms. Height was measured by placing the person against a wall and height marked by a ruler. The height was measured using a non-stretchable measuring tape on a rigid wall surface and reported in meters. This method has been used in other studies which required measurement of BMI. ${ }^{12,13}$

People with diagnosed psychiatric problems were not included in this study. Household members of Mulkharka of this ward were also not included in this study because of relative inaccessibility.

Adult BMI was categorized according to WHO. BMI Asia Classification and for adolescents WHO. BMI chart was used. Caste was categorized as in Nepal Demographic and Health Survey 2006; caste, ethnic and regional identity in Nepal. Duration of Sleep was categorized based on Standard of American Sleep Foundation of USA, i.e. 8 to 10 hours for adolescents and 7 to 9 hours for adults. Sleep quality was assessed according to a question of PSQI.

A person was considered living below poverty line if the person did not have access to at least 2 US dollars per day (Human Development Report, 2007/2008, United Nations). During the study period 1 US dollar was equivalent to NRs. 111. Social role category was based on Kuppuswamy Scale and for students, International Standard Classification of Education(UNESCO) was used. 
Data was entered in SPSS 16 and descriptive statistics applied. Association between categorical variables was determined using chi square test and level of significance was set at 5 percent. Those with poor quality of sleep or abnormal BMI were given health education related to their condition or advised to go for health checkup.

\section{RESULTS}

Table 1: Socio demographic profile of the subjects $(\mathrm{N}-563)$

Gender
1. Male
2. Female
Caste
1. Brahamin/Chhetri
2. Newar
3. Tamang
4. Others
Age group
1. Adolescence
2. Adults

$264(46.9 \%)$

$299(53.1 \%)$

$312(55.4 \%)$

$116(20.6 \%)$

$82(14.6 \%)$

$53(9.4 \%)$

$64(11.4 \%)$

$499(88.6 \%)$

Social role /Occupation

1. Student (Upper Secondary level) 61 (10.8\%)

2. Student(Bachelors \& Masters) $\quad 43(7.6 \%)$

3. Homemakers

$154(27.4 \%)$

4. Farmers

$18(3.2 \%)$

5. Unskilled \& Semi skilled work $163(29.0 \%)$

6. Professional

$93(16.5 \%)$

7. Retired

$15(2.7 \%)$

8. Unemployed

$16(2.8 \%)$

Economic status (Living Below Poverty Line)

$\begin{array}{ll}\text { 1. Yes } & 104(18.5 \%) \\ 2 . \text { No } & 459(81.5 \%)\end{array}$

Use of tobacco products or alcohol

1. Yes $73(13.0 \%)$

2. No $490(87.0 \%)$
The socio demographic profile of the subjects has been shown in Table 1. Out of 563 subjects $53 \%$ were female and the rest were male. Around 89 $\%$ belonged to the adult age group with around 11 $\%$ belonging to adolescent age. The most common caste group was Brahmin/Chhetri constituting 55\%, followed by Newar at almost 21 percent. Tamangs constituted almost 15\% and around 9\% were from other caste groups. Around $18.5 \%$ of the subjects were students, $29.0 \%$ engaged in unskilled and semiskilled work, $27.4 \%$ were homemakers and $16.5 \%$ involved in professional work. Around $82 \%$ of the subjects were living above the poverty line. Eighty-seven percent of the subjects did not consume any tobacco products or alcohol.

\begin{tabular}{|lc|}
\multicolumn{2}{|c|}{ Table 2: BMI of the subjects according to } \\
\multicolumn{1}{|c|}{ Asian classification (N-563) } \\
\hline Underweight & $25(4.4 \%)$ \\
Normal & $191(33.9 \%)$ \\
Overweight & $104(18.5 \%)$ \\
Obese I & $201(35.7 \%)$ \\
Obese II & $42(7.5 \%)$ \\
\hline
\end{tabular}

As shown in Table 2, only 33.9\% (191) had normal BMI and 66.1\%(372) had abnormal BMI. Around $4 \%$ were underweight and $62 \%$ had their BMI more than the normal range, ie overweight (18.5\%), obese I $(35.7 \%)$ \& obese II $(7.5 \%)$. The range of BMI in adults was from 13.9 to 39.6 with mean value of $24.1 \pm 4.2$.

Table 3: Sleep duration and sleep quality of subjects (N-563)

\section{Sleep Duration}

Adequate $\quad 404(71.8 \%)$

Inadequate $159(22.2 \%)$

Sleep Quality (based on a question of PSQI)

Good $\quad 533(94.7 \%)$

Poor $\quad 30(5.3 \%)$

\section{Table 4: Sleep duration and BMI (Asian Classification) (N-563)}

\begin{tabular}{|lcccc|} 
& Normal BMI & Abnormal BMI & P value \\
1. Less sleep duration & $42(7.4 \%)$ & $117(20.8 \%)$ & $159(28.2 \%)$ & \\
2. Adequate sleep duration & $149(26.5 \%)$ & $255(45.3 \%)$ & $404(71.8 \%)$ & 0.02 \\
& $191(33.9 \%)$ & $372(66.1 \%)$ & $563(100 \%)$ & \\
\hline
\end{tabular}

Table 5: Sleep duration and BMI (excluding those with underweight) (N - 538)

\begin{tabular}{|lcccc|}
\hline \multicolumn{5}{|c}{ Table 5: Sleep duration and BMI (excluding those with underweight) (N - 538) } \\
\hline 1. Less sleep duration & Normal BMI & High BMI & & P value \\
2. Adequate sleep duration & $42(7.8 \%)$ & $111(20.6 \%)$ & $153(28.4 \%)$ & \\
& $149(27.7 \%)$ & $236(43.9 \%)$ & $385(71.6 \%)$ & 0.01 \\
& $191(35.5 \%)$ & $347(64.5 \%)$ & $538(100 \%)$ & \\
\hline
\end{tabular}

1. Less sleep duration

2. Adequate sleep duration
Normal BMI

$149(26.5 \%)$
Abnormal BMI

$117(20.8 \%)$

$372(66.1 \%)$
$563(100 \%)$ 
Table 6: Sleep quality and BMI (Asian Classification)

\begin{tabular}{|lccc|} 
& Normal BMI & Abnormal BMI & Total \\
\hline 1. Poor quality sleep & $3(10 \%)$ & $27(90 \%)$ & $30(100 \%)$ \\
2. Good quality sleep & $188(35 \%)$ & $345(65 \%)$ & $533(100 \%)$ \\
\hline
\end{tabular}

Table 7: Sleep duration and BMI in subjects not consuming alcohol or tobacco products (n-90)

\begin{tabular}{|lcccc|}
\hline & Normal BMI & Abnormal BMI & P value \\
\hline 1. Less sleep duration & $34(7.0 \%)$ & $102(20.8 \%)$ & $136(27.8 \%)$ & \\
2. Adequate sleep duration & $134(27.3 \%)$ & $220(44.9 \%)$ & $354(72.2 \%)$ & 0.007 \\
& $168(34.3 \%)$ & $322(65.7 \%)$ & $490(100 \%)$ & \\
\hline
\end{tabular}

Table 8: Sleep duration and BMI in subjects living above poverty line (n-459)

\begin{tabular}{|lcccc|}
\hline & Normal BMI & Abnormal BMI & P value \\
\hline 1. Less sleep duration & $34(7.4 \%)$ & $101(22.0 \%)$ & $135(29.4 \%)$ & \\
2. Adequate sleep duration & $113(24.6 \%)$ & $211(46.0 \%)$ & $324(70.6 \%)$ & 0.04 \\
& $147(32.0 \%)$ & $312(68.0 \%)$ & $459(100 \%)$ & \\
\hline
\end{tabular}

As shown in Table 3, the duration of sleep hours at night ranged from 4.5 to 11 with mean of 7.5 \pm 1.1 . Almost $72 \%$ of the subjects were getting adequate sleep and only 5\% of the subjects felt that the quality of their sleep was poor. As shown by Table 4 less sleep duration was significantly associated with abnormal BMI.

As shown in Table 5, when those with underweight were excluded, significant association was seen between less sleep duration and high BMI i.e. overweight and obese state.

Ninety percent of the subjects who reported poor quality of sleep had abnormal BMI which is high compared to $65 \%$ of those with good quality sleep having abnormal BMI (Table 6).

As seen in Table 7, in subjects not consuming alcohol or tobacco products less sleep duration was significantly associated with abnormal BMI. As seen in Table 8, in subjects living above the poverty line (N-459), less sleep duration was significantly associated with abnormal BMI.

\section{DISCUSSION}

In this study, only $18.5 \%$ of the subjects were living below poverty line which is low in context to Nepal where $56 \%$ of the total population is living below 2 US dollars per day (United Nations Economic \& Social Commission for Asia and Pacific. Statistical Yearbook for Asia and the Pacific 2015: Nepal profile). Less than 5\% were underweight and almost $62 \%$ had BMI above the normal range with $18.5 \%$ and $43.2 \%$ falling in overweight and in obese category respectively.
Back in 1995 WHO had found that the problem of overweight was more than underweight in many developing countries. ${ }^{14}$ Studies done on Nepalese population since 2000 AD have shown prevalence of overweight ranging from 20 to $34 \%$ and prevalence of obesity from 0.4 to $10.14 \% .^{15}$

This study has shown that $22 \%$ of the subjects did not have adequate sleep. The result is similar to that of a study done on adults of Finland where the prevalence of insufficient sleep was shown to be around $20 \% .{ }^{16}$ Another study done on population of Jharkhand, India showed that $36.4 \%$ were not having adequate sleep. ${ }^{17}$

In this study, around 5\% reported having poor quality of sleep. Studies related to sleep disturbance in Scandinavian countries have shown its prevalence varying from 3.2 to $42 \%{ }^{18}$

In this study it was seen that less sleep duration was significantly associated with abnormal BMI. Association between less sleep duration and high BMI was also seen. Data obtained from a study done in rural population of south eastern Iowa, USA showed that less sleep duration on weeknights was associated with higher BMI. ${ }^{19}$ Another crosssectional population-based study in the United States reported that short sleep duration was significantly associated with all categories of abnormal body weight including underweight, overweight, and obesity, whereas longitudinal observation in a large national cohort of Thai adults did not identify any significant association of short sleep duration with underweight. ${ }^{20,21}$ Similarly a study done on Norwegian adolescents showed that the average weekday sleep duration among adolescents in the normal weight range 
was of longer duration compared to that of underweight, overweight and obese adolescents. ${ }^{22}$ Another study conducted in a medical college of Haryana, India in 18-25 aged subjects showed that subjects sleeping less than 7 hours in a day were found to have higher anthropometric parameters compared to those getting adequate sleep..$^{23}$

In this study a large proportion of subjects with poor quality of sleep was shown to have abnormal BMI (90\%). A study done on college students of Arizona State University, United States showed that poor quality of sleep was associated with overweight in young adults. ${ }^{24}$ Many studies have shown that interference of normal sleep patterns leads to metabolic changes which may contribute to the development of obesity as well as cardiovascular disease and diabetes. ${ }^{25}$

In a study done in 66,817 adolescents in China, it was seen that optimal sleep duration of 7 to 8 hours of sleep may prevent overweight and obesity. ${ }^{26}$ Similarly among 245 women enrolled in a 6-month weight-loss program in universities of USA, better subjective sleep quality and sleeping more than 7 hours at night increased the likelihood of successful weight loss. ${ }^{27}$

A study done in university students of Eastern Thailand has shown that alcohol consumption is associated with high BMI. ${ }^{28} \mathrm{~A}$ cross sectional done in adults of Mumbai, India showed that tobacco use was linked to low BMI. ${ }^{29}$ However another cross sectional study done in adults of UK showed that among smokers, the risk of obesity increased with the amount smoked. ${ }^{30}$ Studies have also shown that smoking and alcohol leads to disturbed sleep. ${ }^{31,32}$ However even in those subjects who did not consume alcohol or any forms of tobacco products less sleep duration was significantly associated with abnormal BMI (Table 7).

Finding of a meta-analysis study based on studies of USA, Canada and UK was that individuals having lower income were more likely to develop obesity. ${ }^{33}$ Poverty has also been linked to poor sleep. ${ }^{34,35}$ Even when those subjects living below poverty line were excluded less sleep duration was significantly associated with abnormal BMI (Table 8).
Studies show that the problem of overweight and obesity is rising in many developing countries including Nepal. ${ }^{15} \mathrm{~A}$ lot of evidence suggests that sleeping habits should not be overlooked when prescribing a weight-reduction program. ${ }^{36}$ Due to work pressures, time is valued so much that sleeping is often perceived as a waste of time. However as abnormal sleep features have been linked to abnormal BMI and many other noncommunicable diseases we can no longer ignore the importance of sleep for our physical and mental wellbeing. ${ }^{37}$

Strength of the study: In this community based study $20 \%$ of the total households in a ward were covered. In context to Nepal community based studies at the simplest administrative level i.e. Ward, are scarce. Based on findings of the health related research carried out in local level, ward representatives can mobilize community health workers to improve the health status of the community. Sleep related research has only been carried out in hospital settings and that too is limited in number. As sleep has been linked to many non-communicable diseases, simple sleep related interventions at an earlier stage to prevent and control non communicable diseases may prove to be cost effective in comparison to expensive medical treatment once the disease has progressed to a chronic stage.

Weakness of the study: This study has used Asian BMI category whose application has not been widely accepted in Nepal. Also only a part of PQSI related to quality and duration of sleep has been used to assess sleep. The proportion of adolescents participating in this study is also very less compared to that of adults so the findings may not be generalized for the adolescents. Except for poverty level and consumption of alcohol and tobacco products, this study has not included many variables which may have effect on BMI and sleep.

\section{ACKNOWLEDGEMENTS}

We would like to thank all the undergraduate students of Nepal Medical College who helped in the data collection.

\section{REFERENCES}

1. Nuttall FQ. Body Mass Index: Obesity, BMI and Health: A Critical Review. Nutr Today 2015; 50: 11728.

2. K Park. Preventive Medicine in Obstetrics, Paediatrics and Geriatrics. Park's Textbook of Preventive and Social Medicine. (24th edition). M/s Banaridas Bhanot Publishers 2017: 630.
3. Colten HR, Altevogt BM. Institute of Medicine. Sleep Disorders and Sleep Deprivation: An Unmet Public Health Problem.: The National Academies Press Washington DC 2006.

4. Shepard JW Jr, Buysse DJ, Chesson Al Jr et al. History of development of Sleep Medicine in United States. $J$ Clin Sleep Med 2005; 1: 61-82. 
5. Knutson KL. Does inadequate sleep play a role in vulnerability to obesity? Am J Hum Biol 2012; 24: 361-71.

6. Patel SR. Reduced sleep as an obesity risk factor. Obes Rev 2009; 10: 61-8.

7. St-Onge MP, Shechter A. Sleep disturbances, body fat distribution, food intake and energy expenditure: pathophysiological aspects. Horm Mol Biol Clin Investig 2014; 17: 29-37.

8. Albert SM, Whiton K, Hirshkowitz M. National Sleep Foundation's sleep time duration recommendations: methodology and results summary. Sleep Health 2015; 1: 40-3.

9. Pilcher JJ, Ginter DR, Sadowsky B. Sleep quality versus sleep quantity: Relationships between sleep and measures of health, well-being and sleepiness in college students. J Psychosom Res 1997; 42: 58396.

10. Mesquita G, Reinao R. Nightly use of computers by adolescents: its effect on quality of sleep. Arq Neuropsiquiatr 2007; 65: 428-32.

11. Exelman L, Bulck JV. Bedtime mobile phone use and sleep in adults. Soc Sci Med 2016; 148: 93-101.

12. World Health Organization. The WHO STEPwise approach to non communicable disease risk factor surveillance. World Heal Organ 2017;1-14.

13. Silvanus V, Gupta RKC, Dhakal N. Comparision of Anthropometric Indices as Correlates of Obesity and Hypertension among an Adult population in Kathmandu District. Nepal Med Coll J 2018; 20: 5267.

14. James WPT. WHO recognition of global obesity epidemic. Int'l J Obes 2008; 32: 120-6.

15. Vaidya A, Shakya S, Krettek A. Obesity prevalence in Nepal: public health challenges in a low-income nation during an alarming worldwide trend. Int'l J Environ Res Public Health 2010; 7: 2726-44.

16. Hublin C, Kaprio H, Partinen M, Koskenvuo M. Insufficient Sleep-A Population-Based Study in Adults Sleep 2001; 24: 392-400.

17. Baskey G C,Ghosh S. Prevalence of snoring and insufficient sleep in the population of Jharkhand. Indian J L Sci 2015; 5: 107-10.

18. Liljenberg B, Almqvist M, Hetta J, Roos BE, Agren $\mathrm{H}$. The prevalence of insomnia: the importance of operationally defined criteria. Ann Clin Res 1988; 20: 393-8.

19. Kohatsu ND, Tsai R, Young T, Vangilder R, Burmeister LF, Stromquist AM, Merchant JA. Sleep duration and body mass index in a rural population Arch. Intern Med 2006; 166: 1701-5.

20. Krueger PM, Friedman EM. Sleep duration in the United States: a cross sectional population based study. Am J Epidemiol 2009; 169:1052-63.

21. Yiengprugsawan V, Banwell C, Seubsman SA, Sleigh AC; Thai Cohort Study Team. Short sleep and obesity in a large national cohort of Thai adults. BMJ Open 2012; 2: 1-6 :e000561. doi: 10.1136/ bmjopen-2011-000561. PMID: 22307100; PMCID: PMC3274710.

22. Sivertsen, B., Pallesen, S., Sand, L. et al. Sleep and body mass index in adolescence: results from a large population-based study of Norwegian adolescents aged 16 to 19 years. BMC Pediatr 14 2014. doi:10.1186/1471-2431-14-204.

23. Khullar S,Singh J,Singh M, Kaur H. To Study the Association between Duration of Sleep and BMI in Young Indian Adults. J Clin Diag Res 2018; 12: 4-8.

24. Vargas PA, Flores M,Robles E. Sleep Quality and Body Mass Index in College Students: The Role of Sleep Disturbances. JACH 2014; 62: 534-41.

25. Shankar A, Syamala S, Kalidindi S. Insufficient rest or sleep and its relation to cardiovascular disease, diabetes and obesity in a national, multiethnic sample. PLoS One 2010 Nov 30;5(11):e14189. doi: 10.1371/journal.pone.0014189.

26. Wu, J., Wu, H., Wang, J. et al. Associations between Sleep Duration and Overweight/Obesity: Results from 66,817 Chinese Adolescents. Sci Rep 52015. doi:10.1038/srep16686.

27. Thomson CA, Morrow KL, Flatt SW, et al. Relationship between sleep quality and quantity and weight loss in women participating in a weight-loss intervention trial. Obesity 2012; 20: 1419-25.

28. Booranasuksakul U, Singhato A, Rueangsri N, Prasertsri P. Association between Alcohol Consumption and Body Mass Index in University Students. Asian Pac Isl Nurs J 2019; 4: 57-65.

29. Pednekar MS, Gupta PC, Shukla HC, Hebert JR. Association between tobacco use and body mass index in urban Indian population: implications for public health in India. BMC Public Health 2006; 6: 70 .

30. Dare S, Mackay DF, Pell JP. Relationship between smoking and obesity: a cross-sectional study of 499,504 middle-aged adults in the UK general population PLoS One. 2015;10 doi: 10.1371/journal. pone.0123579.

31. Zhang L, Samet J, Caffo B,Punjabi NM. Cigarette Smoking and Nocturnal Sleep Architecture. Am J Epidemiol 2006; 164:529- 37.

32. Brower KJ. Alcohol's Effects on Sleep in Alcoholics. Alcohol Res Health 2001; 25: 110-25.

33. Kim TJ,Knesebeck O. Income and obesity: what is the direction of the relationship? A systematic review and meta-analysis. BMJ Open 2018; 8: doi: 10.1136.

34. Patel N.P., Grandner M.A., Xie D. et al. Sleep disparity in the population: poor sleep quality is strongly associated with poverty and ethnicity. BMC Public Health 2010. https://doi.org/10.1186/1471-2458-10475.

35. Wu W, Wang W, Dong Z, et al. Sleep Quality and Its Associated Factors among Low-Income Adults in a Rural Area of China: A Population-Based Study. Int'l J Environ Res Public Health 2018; 15. doi:10.3390/ ijerph15092055.

36. Chaput J P, Tremblay A. Adequate sleep to improve the treatment of obesity. CMAJ 2012; 184:1975-76

37. Worley SL. The Extraordinary Importance of Sleep: The Detrimental Effects of Inadequate Sleep on Health and Public Safety Drive an Explosion of Sleep Research. P T. 2018; 43:758-63. 